\title{
Design and Implementation of Artificial Neural Networks to Predict Wind Directions on Controlling Yaw of Wind Turbine Prototype
}

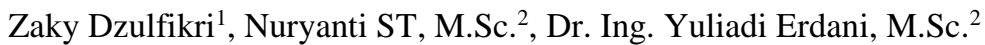 \\ ${ }^{1}$ Mechanical and Manufacturing Engineering, Electromechanical Engineering Study Program \\ ${ }^{2}$ Manufacturing and Mechatronics Automation Engineering, Bandung Polytechnic for Manufacturing \\ Email: zakydzul@gmail.com
}

\begin{abstract}
Wind energy as one of the new renewable energies has an important role in replacing fossil energy sources in Indonesia. To make the wind turbine's performance more efficient in extracting energy from the wind, it is necessary to control the actuation movements pitch and yaw of the horizontal wind turbine. Controlling the yaw actuator can increase the absorption efficiency of the power to the rotor face towards the direction of the wind. The purpose of this work is to be able to predict the direction of the coming wind, then move the turbine rotor into the predicted direction. In this work, a wind turbine prototype is used with a precision of $5.3 \%$, then for the data acquisition section, a wind direction sensor is built to change the amount of wind direction to a quantity that can be measured in units of degrees, and anemometer to measure wind speed. In making the wind direction prediction algorithm, an artificial neural network (ANN) method is used with input parameters such as wind speed, temperature, humidity, pressure, and altitude. Data acquisition is done at one-minute intervals with long data collection for one day, 1072 data are obtained, the data is then fed to the ANN model that has been prepared. Based on the results of tests that have been done, it is found that the lowest mean absolute error that can be achieved in the model is $0.4 \%$ and the model then be used to control turbine yaw movement using straight-forward method of combined method with movement error of seven percent, it is found that using this method can reduce the use of yaw movement while achieving same rotor rpm rate.
\end{abstract}

Keywords - Wind Direction Prediction, Artificial Neural Networks, Wind Turbines, Yaw Control

\section{INTRODUCTION}

The wind is a renewable energy source whose role is very important for the sustainability of renewable energy in the world [1]. Turbine efficiency is one of the main factors to sustain renewable energy. In general, there are already parameter settings in wind turbines so that the power produced is optimal, including variable-speed variable-pitch [2]. Another thing is by regulating the movement of the yaw turbine [3], this rectification can be done by the method of fixed, passive and active yaw.

Active control of axis movement yaw in wind turbines has been discussed by several previous studies [4], [5] achieving desired stability and accuracy. Some motion control approaches adapt various control methods such as Fuzzy Logic [4], and Fuzzy-PID [5]. The direction of the wind in an area can create a very random pattern of direction [6] so that it can endanger the turbines.

Artificial intelligence, one of which is artificial neural networks (ANN) can be trained by feeding training data to produce predictions and understand complex patterns in a system. The use of artificial intelligence to predict wind speed and direction can reduce the tendency of wind direction changes that are too volatile over a short period of time, on the other hand this solution can also reduce the components needed by wind turbines namely Anemometer and Wind vane, which are not effective when used on medium and small turbines.

\section{SYSTEM DESIGN AND METHODOLOGY}

Figure 1 describes the system of research to be conducted. The system consists of several parts, namely sensors, slaves to collect sensor data, the controller as the main controller to separate the data to compute predictions and run the control algorithm yaw, the drive circuit and the driving motor is summarized in a mechanism yaw turbine.
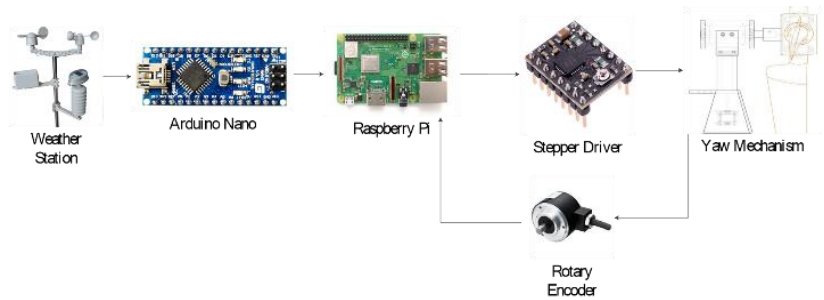

Fig. 1. Overview of System Design

A more detailed explanation of the system is in Figure 2 where each part is described in the workflow, the sensor system consists of several sensor elements including anemometer, wind vane, BME280, and RTC modules for time interruptions, then these values stored by the slave in micro sd which then the data will be used to train the ANN, the ANN model that meets the criteria is then stored in the main controller and will run predictions at intervals of one minute, or when given by the slave, the value is parsed then normalized and entered into the ANN model, the value that comes out must be denormalized so that the value is the same as the value before normalization and then a calculation is made to move the yaw. 


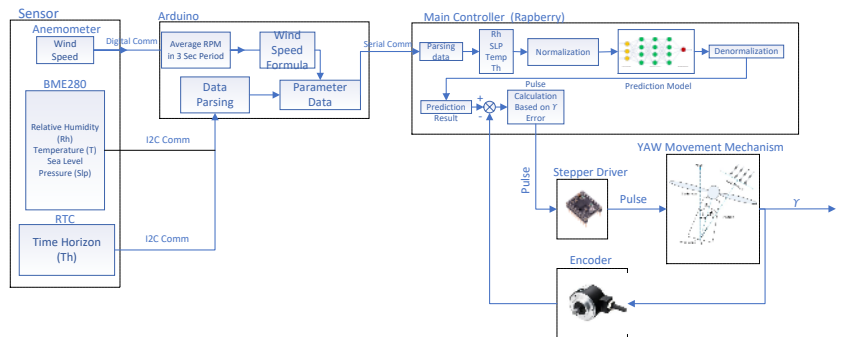

Fig. 2. Overall System Flow Chart

\section{Design of ANN Algorithm}

Figure 3 explains the process of training and making artificial neural networks (ANN) to produce predictive results that are close to the actual value. The first step is to collect sensor parameters data related to the wind direction with a certain time period, then the data is fed to the ANN that has been designed, then ANN will be tested using existing data and see errors that occur between the predicted results and the actual results, if the results if error is as minimum as possible then the trained ANN model is stored in the controller.

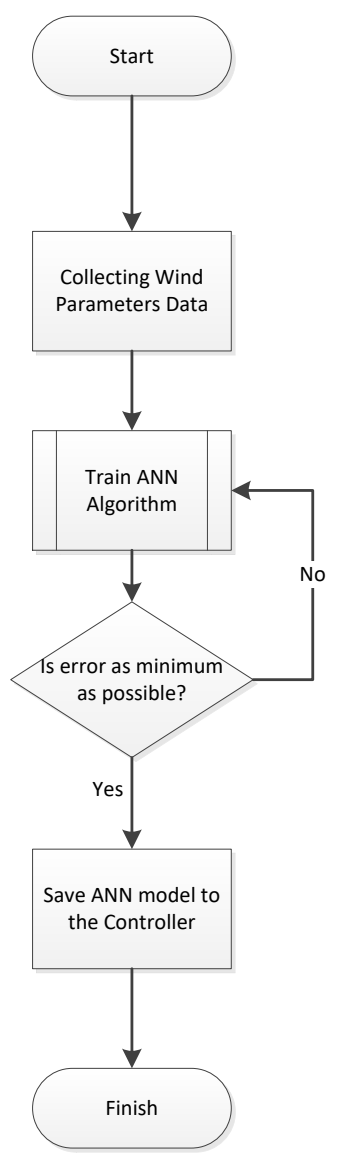

Fig. 3. Flow diagram of making an ANN

In this design, the type of ANN that is used is Multilayer Perceptron (MLP) because the data to be predicted has a high level of non-linearity, if it is Single Layer Perceptron it is not possible to get such output.

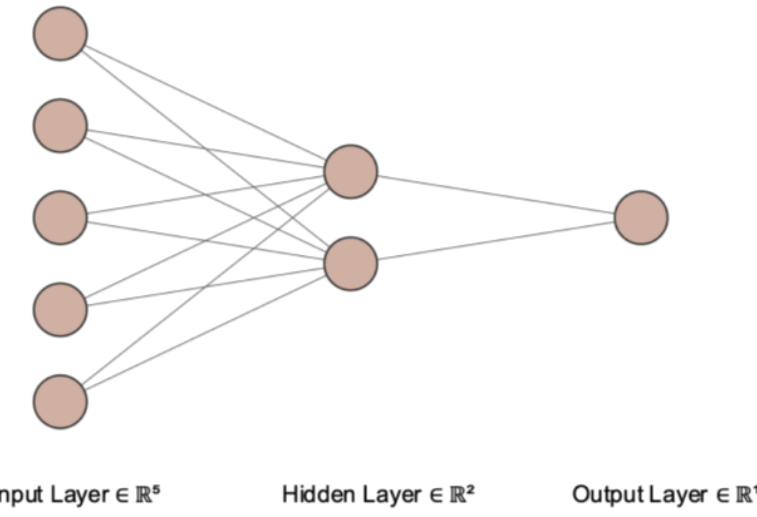

Fig. 4. ANN Architecture

Based on reference [12] stated that the number of nodes in the hidden layer with forwarding approach method is two nodes and rules of thumb method instructs the number of nodes to be between the number of nodes input and number of output nodes, therefore the number of nodes in the hidden layer is two. The other parameters used to construct ANN are in Table 1.

The sigmoid activation function is used because the sigmoid function output and the input range is between 0 to 1. Therefore, this is mainly used for models where we have to predict probabilities as outputs. Because the probability of everything only exists between a range of 0 and 1 , sigmoid is the right choice.

TABLE I. TABLE ANN PARAMETERS

\begin{tabular}{|c|c|}
\hline Parameters & Configurations \\
\hline Activation Function & Sigmoid \\
\hline Optimizer & ADAM \\
\hline Value Dropout & 0.15 \\
\hline Amount of data training & $70 \%$ of all data \\
\hline Amount of validation data & $30 \%$ of all data \\
\hline Index error & Mean Absolute Error (MAE) \\
\hline
\end{tabular}

The error-index used to indicate the parameters of network success in predicting wind direction is the Mean Absolute Error (MAE), MAE measures the average magnitude of errors in a series of estimates, without considering the direction. MAE measures accuracy for continuous variables. The MAE is averaged above the verification sample of the absolute value of the difference between estimates and observations accordingly. MAE is a linear score which means that all individual differences are given the same weighted average. MAE is used in error calculations because of the value of the predicted results because the resulting value is a linear score. MAE is expressed with mathematical equations as follows.

$$
M A E=\frac{1}{n} \sum_{j=1}^{n}\left|y_{j}-\hat{y}_{j}\right|
$$

Where.

$y_{j}=$ value of predicted data 


$$
\begin{aligned}
& \hat{y}_{j}=\text { supposed value } \\
& n=\text { amount of data }
\end{aligned}
$$

\section{Design of Yaw Control Algorithm}

The working principle is explained in Figure 2.5, starting with the reading of several sensors, namely humidity, pressure, and time later the data fed to the controller, the system in the controller will predict wind direction based on sensor input data and ANN models that have been trained before, after getting wind direction relative to the north pole direction of the earth then do the calculation of the number of pulses needed by the movers to go to the destination based on position the direction of the turbine at the time of prediction, after that the controller will send a signal to the driver and the results will be evaluated and if an error occurs then the compensation process will be carried out.

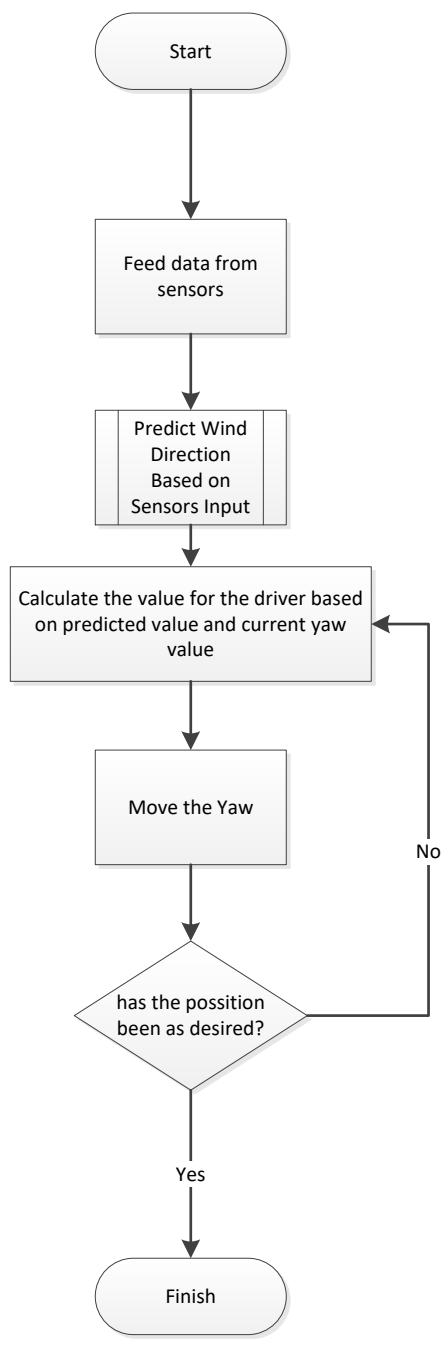

Fig. 5. Flow Chart of Control System Yaw

\section{Yaw Error Effect on Absorbing Wind Energy}

Reference [28] states that the error yaw of \pm 20 degrees is the greatest error tolerance is applied on wind turbines in the industry, Figure 2.6 shows that the value of error yaw of the population of fewer than 20 degrees results in the best condition to absorb wind energy.

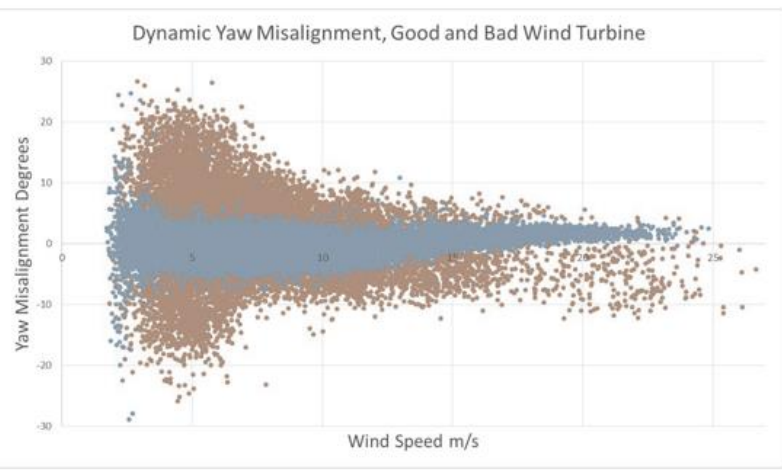

Fig. 6. Dynamic Yaw Misalignment in Respect of Wind Speed

\section{TESTING RESUlT}

Parameter data are taken based on reference [13] that the parameters in Table 1 and Table 2 can be used to predict wind direction.

TABLE II

INPUT AND OUTPUT DATA ON NOAA DATA

\begin{tabular}{|c|c|c|c|c|c|}
\hline Temp & Dewpt & RHx & Slp & Spd & Dir \\
\hline $\mathbf{2 5 . 2}$ & 19.6 & 71 & 1014.7 & 2.1 & 60 \\
\hline $\mathbf{2 8}$ & 20.4 & 63 & 1012.8 & 3.1 & 330 \\
\hline $\mathbf{2 4}$ & 20.9 & 83 & 1010.6 & 2.6 & 330 \\
\hline $\mathbf{2 2 . 2}$ & 20.7 & 91 & 1014.4 & 2.6 & 300 \\
\hline $\mathbf{2 1 . 8}$ & 21.2 & 96 & 1016 & 1.5 & 300 \\
\hline $\mathbf{2 1 . 8}$ & 21.2 & 96 & 1012.9 & 1.5 & 300 \\
\hline $\mathbf{2 2 . 2}$ & 21 & 93 & 1013.8 & 1.5 & 330 \\
\hline $\mathbf{2 0 . 4}$ & 19.5 & 95 & 1014.9 & 1.5 & 120 \\
\hline $\mathbf{2 6 . 4}$ & 20.7 & 71 & 1014.7 & 1.5 & 90 \\
\hline
\end{tabular}

The first dataset to be analyzed is derived from data acquisition sensor with a time interval of data retrieval for one minute for approximately one day, with a total of 1079 data and six parameters measured while data from NOAA has an interval of three hours with data retrieval for one year totaling 2205 data.

TABLE III. INPUT AND OUTPUT DATA ON NOAA DATA

\begin{tabular}{|c|c|c|c|c|c|}
\hline Temp & Dewpt & RHx & Slp & Spd & Dir \\
\hline $\mathbf{3 0 . 5 8}$ & 919.83 & 808.58 & 42.41 & 10.2 & 332 \\
\hline $\mathbf{3 0 . 4 8}$ & 919.84 & 808.49 & 42.55 & 6.9 & 319 \\
\hline $\mathbf{3 0 . 5 7}$ & 919.81 & 808.74 & 42.42 & 3 & 315 \\
\hline $\mathbf{3 0 . 5 9}$ & 919.85 & 808.38 & 42.33 & 7.8 & 319 \\
\hline $\mathbf{3 0 . 5 6}$ & 919.85 & 808.37 & 42.6 & 4.8 & 243 \\
\hline $\mathbf{3 0 . 4 8}$ & 919.88 & 808.09 & 42.67 & 0 & 229 \\
\hline $\mathbf{3 0 . 4 4}$ & 919.84 & 808.43 & 43.27 & 0.3 & 240 \\
\hline $\mathbf{3 0 . 3 6}$ & 919.86 & 808.29 & 43.71 & 16.8 & 246 \\
\hline $\mathbf{2 9 . 9 9}$ & 919.8 & 808.83 & 44.36 & 27.6 & 277 \\
\hline
\end{tabular}




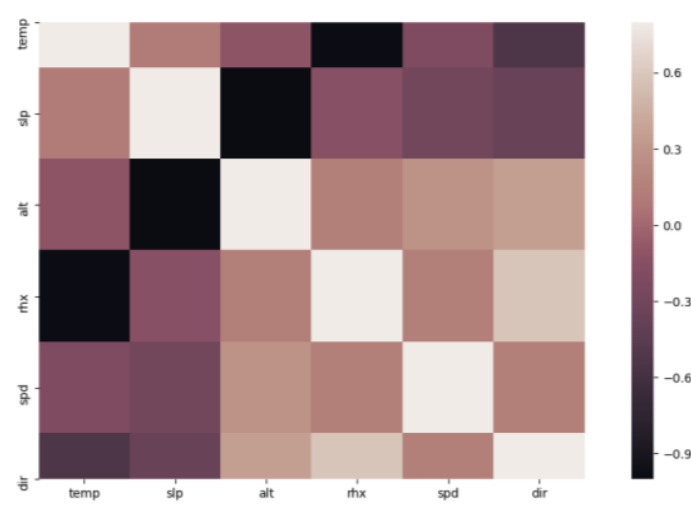

(a)

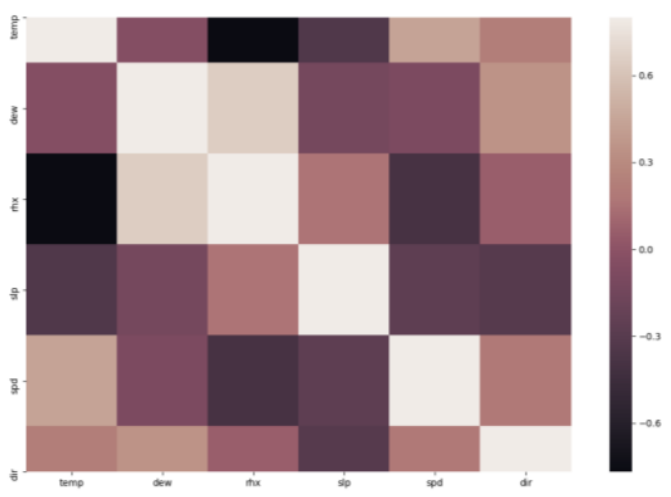

(b)

Fig. 7. Interrelation Graph Between Data Acquisition Parameters (a), NOAA Data (b).

Figure 7 shows the value of the relationship between parameters, the value is obtained by calculating the value of each parameter with other parameters using the Pearson coefficient which is expressed by.

$$
r_{x y}=\frac{N \sum x_{i} y_{i}-\sum x_{i} \sum y_{i}}{\sqrt{N \sum x_{i}{ }^{2}-\left(\sum x_{i}\right)^{2}} \sqrt{N \sum y_{i}{ }^{2}-\left(\sum y_{i}\right)^{2}}}
$$

Where:

The value of $\mathrm{r}$ is in the range 1 to -1 and $\mathrm{y}$ is the target parameter, and $\mathrm{x}$ is the variable parameter.

So that in Figure 8 shows that bright colors have a high correlation and dark colors have a high correlation also only in the opposite gradient

\section{Analysis of Artificial Neural Networks}

After the data preparation is done then the training process or training in ANN with the data that has been prepared, the parameters used in training ANN are as follows Table 4. Batch values determine how much data input has entered before the weight value is updated.

TABLE IV

Data Training and Testing Configuration

\begin{tabular}{|c|c|}
\hline Parameters & Configuration \\
\hline Number of Epochs & 60 \\
\hline Batch Value & 2 \\
\hline
\end{tabular}

\begin{tabular}{|c|c|}
\hline $\begin{array}{c}\text { Amount of Training } \\
\text { Data }\end{array}$ & $70 \%$ \\
\hline $\begin{array}{c}\text { Amount of Validation } \\
\text { Data }\end{array}$ & $30 \%$ \\
\hline
\end{tabular}

The results of the training plot show the value achieved by the data acquisition results is better with $\mathrm{MAE}=0.0482$ in training and 0.227 invalidations compared to using data from NOAA which has MAE $=0.2028$ in training and 0.259 invalidations, this shows that the value data collection intervals affect the learning model carried out ANN.

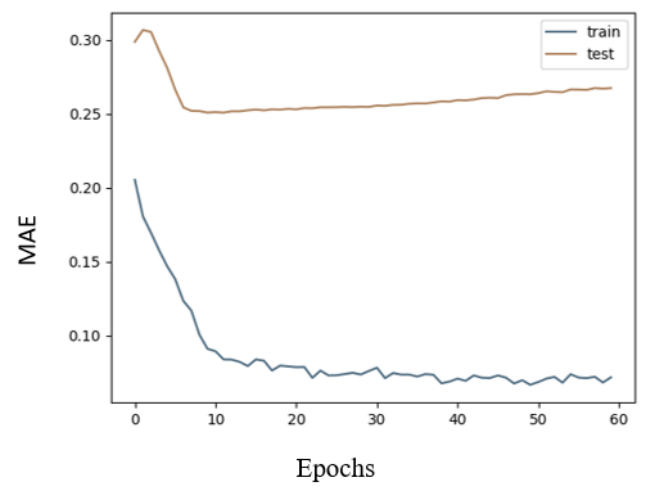

(a)

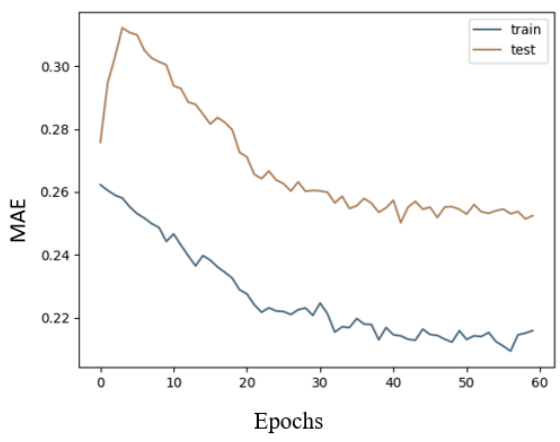

(b)

Fig. 8. Plot Error Process of Process Training ANN Using Data Results Acquisition (a), NOAA Data (b).

A comparison of the number of epochs used can be seen in Table 5 which shows that the value of epochs 60 has an optimum performance where the model does not show underfitting or overfitting.

TABLE V. COMPARISON OF NUMBER OF EPOCHS

\begin{tabular}{|c|c|c|}
\hline $\begin{array}{c}\text { Number of } \\
\text { Epochs }\end{array}$ & $\begin{array}{c}\text { MAE } \\
\text { Training }\end{array}$ & $\begin{array}{c}\text { Value MAE } \\
\text { Value Validation }\end{array}$ \\
\hline $\mathbf{3 0}$ & 0.0542 & 0.230 \\
\hline $\mathbf{6 0}$ & 0.0482 & 0.226 \\
\hline $\mathbf{7 0}$ & 0.0472 & 0.256 \\
\hline
\end{tabular}

Predictive value compared with existing data values but has never been seen by an ANN so this value represents a case where the value which is predicted to be unprecedented, the validation data uses thirty percent of the overall data. 


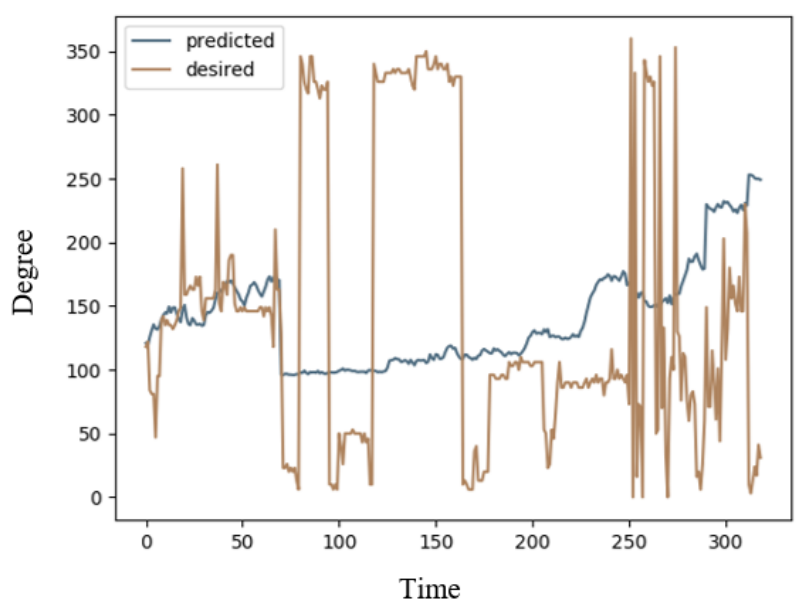

(a)

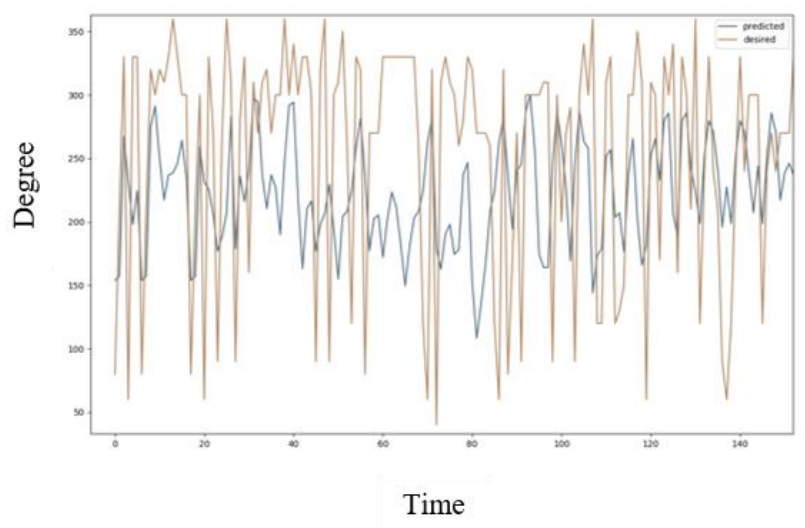

(b)

Fig. 9. Plot Error Process of Process Training ANN Using Data Results Acquisition (a), NOAA Data (b).

The results of the graph in Figure 10 shows the predicted value approaching the target value at power fluctuations that are not high, when faced with data that rises rapidly or falls rapidly then the model has difficulty predicting the value that should be, Figure $b$ indicates that high fluctuation values cannot be followed by the ANN model even though it has a tendency towards the expected target. The value MAE for the model with data acquisition is 9,924 while for NOAA data is 9,566 .

\subsection{Control Analysis Yaw}

Motor Stepper testing is done by entering the value input using the serial monitor on the Arduino IDE. The input value is the number of steps desired on the motor to spin. Then the value is converted to units of degrees. The degree conversion is calculated to determine the number of steps that must be applied to the motor because stepper is used has a resolution of $1.8^{\circ}$. The step count is then converted to data type integer because the number of steps must be a non-decimal number. The test results of motor movement stepper can be seen in Table 6

TABLE VI. MOTOR MOVEMENT TeSting Results STEPPER

\begin{tabular}{|c|c|c|}
\hline Set (Degrees) & $\begin{array}{c}\text { Actual } \\
\text { (Degrees) }\end{array}$ & Error (Percent) \\
\hline 45 & 42 & 6.7 \\
\hline
\end{tabular}

\begin{tabular}{|c|c|c|}
\hline 135 & 126 & 6.7 \\
\hline 45 & 41 & 8.2 \\
\hline 135 & 125 & 7.4 \\
\hline 30 & 31 & 2.7 \\
\hline 60 & 63.7 & 6.7 \\
\hline 90 & 88.9 & 1.2 \\
\hline 10 & 9.8 & 2 \\
\hline 270 & 271,6 & 0.59 \\
\hline 5 & 4.2 & 16 \\
\hline 2 & 1.4 & 30 \\
\hline 360 & 357.7 & 0.69 \\
\hline 120 & 121.1 & 0.917 \\
\hline Average Error & 7 \\
\hline & & \\
\hline
\end{tabular}

Due to the results of predictions that sometimes show errors that are higher than the tolerance value (20 degrees) then it is decided to keep using the wind vane as a compensation for the inaccuracy of the predicted results, then the predictive value is used as the main reference in the control process, the value is combined with the previous position value and averaged with the equation.

Where.

$$
\theta_{a}=\arctan \left(c_{a}, s_{a}\right)
$$

$$
\begin{aligned}
s_{a} & =\frac{1}{n} \sum_{i=1}^{n} \sin \theta_{i} \\
c_{a} & =\frac{1}{n} \sum_{i=1}^{n} \cos \theta_{i}
\end{aligned}
$$

So we get the data in Table 7 .

TABLE VII. TABLE CONTROL OF DiRECTION TURBINE

\begin{tabular}{|c|c|c|c|c|c|}
\hline $\begin{array}{c}\text { Wind } \\
\text { Vane }\end{array}$ & $\begin{array}{c}\text { Old } \\
\text { Position }\end{array}$ & $\begin{array}{c}\text { Predicti } \\
\text { on } \\
\text { Result }\end{array}$ & $\begin{array}{c}\text { Optimu } \\
\mathbf{m} \\
\text { Position }\end{array}$ & $\begin{array}{c}\text { Wind } \\
\text { Vane } \\
\text { Delta } \\
\text { Position }\end{array}$ & $\begin{array}{c}\text { Optimum } \\
\text { Delta } \\
\text { Position }\end{array}$ \\
\hline (Degree) & (Degree) & (Degree) & (Degree) & (Degree) & (Degree) \\
\hline 74 & 74 & 254,2 & 280 & - & - \\
\hline 81 & 280 & 254,1 & 273 & 7 & 7 \\
\hline 347 & 273 & 253 & 289 & 266 & 16 \\
\hline 29 & 289 & 254 & 303,2 & 318 & 14.2 \\
\hline 12 & 303,2 & 254,6 & 308,4 & 17 & 5.2 \\
\hline 171 & 308,4 & 254,9 & 248 & 159 & 60,4 \\
\hline 230 & 248 & 254 & 244 & 59 & 4 \\
\hline 42 & 244 & 254,4 & 272 & 188 & 28 \\
\hline 25 & 272 & 254,9 & 293,8 & 17 & 21.8 \\
\hline \multicolumn{2}{|l|}{} & Rata-rata Delta & & 128,875 & 19,575 \\
\hline
\end{tabular}


Table 7 shows that the predicted results are unlikely to change in a short time span while the position wind vane changed dramatically in a short period of time, by averaging the value of the old position, the predicted results and the value of the wind vane the optimal position value is achieved with the use of yaw movements to a minimum, with the average delta showing a small value for optimal control.

The process of processing sensor data certainly requires time and the process of movement of the yaw also takes time, therefore in this analysis, the processing time test is performed on the system shown in Table 8 .

\section{TABLE VIII. TABLE CONTROL OF DiRECTION TURBINE}

\begin{tabular}{|c|c|}
\hline No. & Processing Time (Seconds) \\
\hline 1. & 0.197 \\
\hline 2. & 0.17 \\
\hline 3. & 0.159 \\
\hline 4. & 0.166 \\
\hline 5. & 0.182 \\
\hline 6. & 0.245 \\
\hline 7. & 1.1 \\
\hline 8. & 0.13 \\
\hline 9. & 1.66 \\
\hline 10. & 0.17 \\
\hline average & 0,4179 \\
\hline
\end{tabular}

The experimental results in Table 8 show that the average time of processing data on the system is 0.4179 seconds, this shows that the data processing time is fast categorized based on the time interval of one-minute changes.

Further yaw movement time compared to the calculation of time should be, the formula for the speed of movement of the yaw can be expressed with.

$$
\omega=\frac{v}{f}
$$

Where.

$$
\begin{aligned}
& \omega=\text { angular velocity in (degrees / seconds) } \\
& f=\text { seconds / step } \\
& v=\text { step / degrees } \\
& \text { with. } \\
& f=0.01 \text { seconds } \\
& v=0.05625 \text { step / degree }
\end{aligned}
$$

Then the value with an angular velocity of yaw 5.62 degrees/second is tested with the results in Table 9.

TABLE IX.

$$
\text { YAW Movement Time Test }
$$

\begin{tabular}{|c|c|c|c|c|}
\hline No. & $\begin{array}{c}\text { Angle } \\
\text { Change } \\
\text { (Degrees) }\end{array}$ & $\begin{array}{c}\text { Calculatio } \\
\text { n Time } \\
\text { (Seconds) }\end{array}$ & $\begin{array}{c}\text { Trial Time } \\
\text { (Seconds) }\end{array}$ & $\begin{array}{c}\text { Difference } \\
\text { (Seconds) }\end{array}$ \\
\hline 1. & 10 & 1.78 & 1.82 & 0.04 \\
\hline 2. & 20 & 3.56 & 3.72 & 0.16 \\
\hline
\end{tabular}

\begin{tabular}{|c|c|c|c|c|}
\hline 3. & 60 & 10.68 & 10,88 & 0.2 \\
\hline 4 & 90 & 16.01 & 17.02 & 1.01 \\
\hline 5. & 120 & 21.35 & 21.45 & 0.1 \\
\hline 6. & 150 & 26.7 & 26.94 & 0.24 \\
\hline 7. & 210 & 37.4 & 38.2 & 0.8 \\
\hline 8. & 260 & 46.3 & 47.4 & 1.1 \\
\hline \multicolumn{5}{|c|}{ Average } \\
\hline
\end{tabular}

From the results of Table 9, it is found that the average value of the time difference in the actual calculation and testing is 0.456 seconds with an angular velocity of 5.62 degrees/second.

Load on yaw is calculated from the maximum force that can be held by the yaw turbine before, this analysis does not include the maximum wind speed value that can be held. For the calculation of the maximum force expressed with the following equation.

\section{Where}

$$
\tau=r F \sin \theta
$$

$$
\begin{aligned}
& r=\text { Arm length (m) } \\
& F=\text { force acting on the propeller (N) } \\
& \theta=\text { Angle deviation in yaw (degrees) }
\end{aligned}
$$

If the stepping motor torque resistance value is $1.3 \mathrm{Nm}$ and arm length is $13 \mathrm{~cm}$, the maximum force that can occur in the blades is $10 \mathrm{~N}$ with a maximum angle deviation of 90 degrees.

After controlling the turbine yaw, rotor rotation data and wind speed are taken at the same time, controlling the yaw used is controlling hybrid (wind vane and prediction) and wind vane, with the results in Table 10.

TABLE X. COMPARISON OF ROTATIONAL ROTORS IN CONTROLLING HYBRID AND WIND VANE

\begin{tabular}{|c|c|c|c|c|}
\hline \multirow{2}{*}{ No } & \multicolumn{2}{|c|}{ Hybrid } & \multicolumn{2}{c|}{ Wind vane } \\
\cline { 2 - 5 } & RPM Wind & $\begin{array}{r}\text { RPM } \\
\text { Rotor }\end{array}$ & RPM Wind & $\begin{array}{r}\text { RPM } \\
\text { Rotor }\end{array}$ \\
\hline 1. & 29 & 30 & 77 & 4 \\
\hline 2. & 52 & 29 & 91 & 49 \\
\hline 3. & 61 & 43 & 82 & 47 \\
\hline 4. & 74 & 37 & 70 & 65 \\
\hline 5. & 24 & 25 & 68 & 35 \\
\hline 6. & 61 & 22 & 51 & 54 \\
\hline 7. & 71 & 22 & 63 & 77 \\
\hline 8. & 74 & 41 & 77 & 35 \\
\hline Average & 56 & 31 & 72 & 46 \\
\hline Ratio & \multicolumn{2}{|c|}{0.55704698} & 0.633437175 \\
\hline
\end{tabular}

Table 11 shows that the ratio value of the hybrid method is lower compared to using wind vane, but the value is very much influenced by the state of the wind at that time, so that deeper research is needed to see the effect of the two control methods on rotor speed. 
Table 11 Testing with Hybrid Method

\begin{tabular}{|c|c|c|c|}
\hline Parameter & 30 minutes & 60 minutes & 120 minutes \\
\hline $\begin{array}{c}\text { Wind RPM } \\
\text { Average }\end{array}$ & 45 & 37 & 56 \\
\hline $\begin{array}{c}\text { Rotor RPM } \\
\text { Average }\end{array}$ & 29 & 22 & 35 \\
\hline Ratio & 0.64 & 0.69 & 0.625 \\
\hline
\end{tabular}

Table 12 Testing With the Wind Vane Method

\begin{tabular}{|c|c|c|c|}
\hline Parameter & 30 minutes & 60 minutes & 120 minutes \\
\hline $\begin{array}{c}\text { Average Wind } \\
\text { RPM }\end{array}$ & 34 & 43 & 52 \\
\hline $\begin{array}{c}\text { Average Rotor } \\
\text { RPM }\end{array}$ & 29 & 33 & 34 \\
\hline Ratio & 0.89 & 0.76 & 0.65 \\
\hline
\end{tabular}

From the test results in Table 11 and Table 12 it is found that the rotor rotation value affects the wind speed value, and the longer the value of the ratio test it was found that the two different controls tend to go to the same value with the need for further analysis of the value of the long trial time.

\section{CONCLUSION}

Based on the testing and analysis conducted, it can be concluded that. The artificial neural network that is built can predict the direction of the wind coming with a mean absolute error of 0.482 at one-minute data intervals in the training process, and 9,924 for testing results, while for data with three-hour intervals obtained the value of mean absolute error of 0.228 on a 9.566 in the training process and testing process. The yaw movement can be reduced using hybrid method and still resulting in a no-rpm loss. The yaw turbine movement obtained an average of 7 percent movement error against the setpoint to be achieved.

\section{SugGestions}

In this study the ANN that was built still produces a fairly high error, this is because the input parameters used are low, and the sensor used to acquire data is not a sensor commonly used in industry so the data obtained is not too accurate and precise, therefore it is recommended to use a sensor that has been tested with a variety of data collection time intervals and the number of input parameters that are reproduced.

\section{REFERENCES}

[1] Global Wind Energy Council, "Global Wind Energy Outlook 2016," GWEC, 2016.

[2] E. Muljadi and CP Butterfield, "Pitch-Controlled Variable-Speed Wind Turbine Generation," IEEE Transactions on Industry Applications, vol. 37, no. 1, pp. 240-246, 2001.

[3] N. Hure, R. Turnar, M. Vasak, and G. Ben`ci'c, "Optimal Wind Turbine Yaw Control Supported with Very Short-term Wind Predictions," 2015 IEEE International Conference on Industrial Technology (ICIT), pp. 385-391, 2015.

[4] A. Torabi, E. Tarsaii, and SKM Mashhadi, "Fuzzy Controller Used in Yaw System of Wind Turbine noise," Journal of mathematics and computer science 8, pp. 105-112, 2014.

[5] F.-Q. Chen and J.-M. Yang, "Fuzzy PID Controller Used in Yaw System of Wind Turbine," 3rd International Conference on Power Electronics Systems and Applications, pp. 1-4, 2009.

[6] G. Li and J. Shi, "On comparison of three artificial neural networks for wind speed forecasting," Applied Energy, vol. 87, no. 7, pp. 23132320, 2010.
[7] SP Kani and MM Ardehali, "Very short-term wind speed prediction: A new artificial neural network-Makrov Chain model," Energy Conversion and Management, vol. 52, no. 1, pp. 738-745, 2011.

[8] BD Lakshmi and K. Sujatha, "Artificial Neural Networks for Wind Speed Direction," International Journal of Computer Technology and Applications, vol. 4, no. 9, pp. 179-185, 2016.

[9] VDI (2004), VDI 2206 - Design methodology for mechatronic systems, Düsseldorf: The Association of German Engineers (VDI), 2004.

[10] J. Wieringa, "Evaluation and Design of Wind Vanes, " Journal of Applied Meteorology, vol. 6, pp. 1114-1122, 1967.

[11] Á. Sanz-Andrés, S. Pindado and a. F. Sorribes-Palmer, "Mathematical Analysis of the Effect of Rotor Geometry on Cup Anemometer Response," The Scientific World Journal, 2014.

[12] FS Panchal and M. Panchal, "Review on Methods of Selecting Numbers of Hidden Nodes in Artificial Neural Network, "International Journal of Computer Science and Mobile Computing, vol. 3, no. 11, pp. 455-464, 2014.

[13] H.-J. Wagner and J. Mathur, Introduction to Wind Energy Systems, Heidelberg: Springer, 2009.

[14] Z. Whu and H. Wang, "Research on Active Yaw Mechanism of Small Wind Turbines," Energy Procedia 16, pp. 53-57, 2012.

[15] FA Farret, LL Pfitscher, and DP Bemardon, "Active Yaw Control with Sensorless Wind Speed and Direction," in Proceedings of the 2000 Third IEEE International Caracas Conference on Devices, Circuits and Systems (Cat. No .00TH8474), Caracas, 2000.

[16] M. Dalto, J. Maatusko and M. Vasak, "Deep neural networks for ultrashort-term wind forecasting," in IEEE International Conference on Industrial Technology, Seville, 2015.

[17] M. Rouse, "WhatIs.com," Tech Target, January 2016. [Online]. Available: https://whatis.techtarget.com/definition/wind-turbine. [Accessed November 11, 2018]

[18] AR Jha, Wind Turbine Technology, Florida: Taylor and Francis Group, 2011.

[19] M. Flasiński, Introduction to Artificial Intelligence, Basel: Springer, 2016.

[20] YR Senoaji, "Design of Building Control of YAW in Prototype Wind Turbines, "Polman Bandung, Bandung, 2018.

[21] W.-Y. Chang, "A Literature Review of Wind Forecasting Methods," Journal of Power and Energy Engineering, vol. 2, pp. 161-168, 2014.

[22] D. Svozil, V. KvasniEka and J. Pospichal, "Introduction to multi-layer feed-forward neural networks," Chemometrics and Intelligent Laboratory Systems, vol. 39, pp. 43-62, 1997.

[23] E. Rijanto, A. Muqorobin, and AS Nugraha, "Design of a Yaw Positioning Control System for," International Journal of Applied Engineering Research, vol. 6, pp. 2327-2340, 2011.

[24] United States Environmental Agency, "Meteorological Monitoring Guidance for Regulatory Modeling Applications," United States Environmental Agency, North Carolina, 2000.

[25] WebFinance Inc., "BussinesDictionary," [Online]. Available: http://www.businessdictionary.com/definition/regression.html. [Accessed July 24, 2019].

[26] S. Dongran, J. Yang, X. Fan, Y. Liu, A. Liu, G. Chen, and YH Joo, "Maximum Power Extraction for Wind Turbines Through a Yaw Control Novel," Energy Conversion and Management, pp. . 587-599, 2018.

[27] S. Dongran, Y. Jian, Y. Liu, M. Su, A. Liu, and YH Joo, "Wind Direction Prediction for Yaw Control of Wind Turbines," International Journal of Control, Automation and Systems 15, vol. X, pp. 1-9, 2017.

[28] HS Pedersen and EG Marin, "Yaw Misalignment and Power Curve Analysis," in EWEA Analysis of Operating Wind Farms 2016, Bilbao, 2016.

[29] S. Wan, L. Cheng, and X. Sheng, "Effect of Yaw Error on Wind Turbine Running Characteristics Based on the Equivalent Wind Speed Model," Energies, vol. 8, pp. 8286-6301, 2015.

[30] T. Ouyang, A. Kusiak, and Y. He, "Predictive Model of Yaw Error in Wind Turbine," Energy, vol. 123, pp. 119-130, 2017. 